University of Nebraska - Lincoln

DigitalCommons@University of Nebraska - Lincoln

USDA Wildlife Services - Staff Publications

U.S. Department of Agriculture: Animal and Plant Health Inspection Service

2013

Surveillance and movements of Virginia opossum (Didelphis virginiana) in the bovine tuberculosis region of Michigan

\author{
W. D. Walter \\ United States Department of Agriculture, wdwalter@psu.edu \\ Justin W. Fischer \\ USDA/APHIS/WS National Wildlife Research Center, Justin.w.fischer@aphis.usda.gov \\ C. W. Anderson \\ United States Department of Agriculture \\ D. R. Marks \\ United States Department of Agriculture \\ T. J. Deliberto \\ USDA/APHIS/WS National Wildlife Research Center, Thomas.J.DeLibertot@aphis.usda.gov
}

See next page for additional authors

Follow this and additional works at: https://digitalcommons.unl.edu/icwdm_usdanwrc

Part of the Life Sciences Commons

Walter, W. D.; Fischer, Justin W.; Anderson, C. W.; Marks, D. R.; Deliberto, T. J.; Robbe-Austerman, S.; and VerCauteren, K. C., "Surveillance and movements of Virginia opossum (Didelphis virginiana) in the bovine tuberculosis region of Michigan" (2013). USDA Wildlife Services - Staff Publications. 1606.

https://digitalcommons.unl.edu/icwdm_usdanwrc/1606

This Article is brought to you for free and open access by the U.S. Department of Agriculture: Animal and Plant Health Inspection Service at DigitalCommons@University of Nebraska - Lincoln. It has been accepted for inclusion in USDA Wildlife Services - Staff Publications by an authorized administrator of DigitalCommons@University of Nebraska - Lincoln. 


\section{Authors}

W. D. Walter, Justin W. Fischer, C. W. Anderson, D. R. Marks, T. J. Deliberto, S. Robbe-Austerman, and K. C. VerCauteren 


\title{
Surveillance and movements of Virginia opossum (Didelphis virginiana) in the bovine tuberculosis region of Michigan
}

\author{
W. D. WALTER ${ }^{1 *}$, J. W. FISCHER ${ }^{1}$, C. W. ANDERSON ${ }^{1}$, D. R. MARKS ${ }^{2}$, \\ T. DELIBERTO ${ }^{1}$, S. ROBBE-AUSTERMAN ${ }^{3}$ AND K. C. VERCAUTEREN ${ }^{1}$ \\ ${ }^{1}$ United States Department of Agriculture, Animal and Plant Health Inspection Services, Wildlife Services, \\ National Wildlife Research Center, Fort Collins, CO, USA \\ ${ }^{2}$ United States Department of Agriculture, Animal and Plant Health Inspection Services, Wildlife Services, \\ National Wildlife Disease Program, Okemos, MI, USA \\ ${ }^{3}$ United States Department of Agriculture, Animal and Plant Health Inspection Services, Veterinary Services, \\ National Veterinary Services Laboratories, Ames, IA, USA
}

Received 30 October 2012; Final revision 22 February 2013; Accepted 25 February 2013; first published online 26 March 2013

\section{SUMMARY}

Wildlife reservoir hosts of bovine tuberculosis (bTB) include Eurasian badgers (Meles meles) and brushtail possum (Trichosurus vulpecula) in the UK and New Zealand, respectively. Similar species warrant further investigation in the northern lower peninsula of Michigan, USA due to the continued presence of bTB on cattle farms. Most research in Michigan, USA has focused on interactions between white-tailed deer (Odocoileus virginianus) and cattle (Bos taurus) for the transmission of the infectious agent of bTB, Mycobacterium bovis, due to high deer densities and feeding practices. However, limited data are available on medium-sized mammals such as Virginia opossum (Didelphis virginiana; hereafter referred to as opossum) and their movements and home range in Michigan near cattle farms. We conducted surveillance of medium-sized mammals on previously depopulated cattle farms for presence of $M$. bovis infections and equipped opossum with Global Positioning System (GPS) technology to assess potential differences in home range between farms inside and outside the bTB core area that has had cattle test positive for $M$. bovis. On farms inside the bTB core area, prevalence in opossum was comparable $[6 \%, 95 \%$ confidence interval (CI) $2 \cdot 0-11 \cdot 0]$ to prevalence in raccoon (Procyon lotor; 4\%, 95\% CI 1.0-9.0, $P=0 \cdot 439$ ) whereas only a single opossum tested positive for $M$. bovis on farms outside the bTB core area. The prevalence in opossum occupying farms that had cattle test positive for $M$. bovis was higher $(6 \cdot 4 \%)$ than for opossum occupying farms that never had cattle test positive for $M$. bovis $(0 \cdot 9 \%, P=0 \cdot 01)$. Mean size of home range for $50 \%$ and $95 \%$ estimates were similar by sex $(P=0.791)$ both inside or outside the bTB core area $(P=0 \cdot 218)$. Although surveillance efforts and home range were not assessed on the same farms, opossum use of farms near structures was apparent as was selection for farms over surrounding forested habitats. The use of farms, stored feed, and structures by opossum, their ability to serve as vectors of $M$. bovis, and their propensity to ingest contaminated sources of M. bovis requires additional research in Michigan, USA.

Key words: Bovine tuberculosis (bTB), home range, indirect disease transmission, Mycobacterium bovis, resource selection analysis, surveillance.

\footnotetext{
* Author for correspondence: Dr W. D. Walter, U.S. Geological Survey, Pennsylvania Cooperative Fish \& Wildlife Research Unit, Pennsylvania State University, 403 Forest Resources Bldg, University Park, PA 16802, USA.

(Email: wdwalter@psu.edu)
} 


\section{INTRODUCTION}

Bovine tuberculosis (bTB) is an infectious disease caused by a bacterium, Mycobacterium bovis, affecting both domestic and wild animals worldwide. In Michigan, USA, bTB was discovered in white-tailed deer (Odocoileus virginianus) following the 1994 firearm deer season in portions of Alpena, Alcona, Oscoda, and Montmorency counties, hereafter referred to as the bTB core area [1]. In addition to deer, other wildlife that tested positive for M. bovis in Michigan include elk (Cervus elaphus), coyote (Canis latrans), raccoon (Procyon lotor), black bear (Ursus americanus), bobcat (Lynx rufus), Virginia opossum (Didelphis virginiana; hereafter referred to as opossum), red fox (Vulpes vulpes), and feral cat (Felis catus) [2, 3]. Between 1994 and 2010, 36 cattle (Bos taurus) farms tested positive for $M$. bovis in seven counties (29 beef herds, seven dairy herds) with transmission likely from a variety of sources $[4,5]$. Although considerable white-tailed deer reductions have occurred since 1994, new infections and recurring infections continue to plague Michigan farmers.

Other wildlife reservoir hosts of $M$. bovis other than white-tailed deer, include the brushtail possum (Trichosurus vulpecula) in New Zealand and the Eurasian badger (Meles meles) in the UK indicating the potential for a multi-host system further complicating $M$. bovis control [6, 7]. High population densities, simultaneous sharing of dens, and large social groups have contributed to the persistence of $M$. bovis in brushtail possums and badgers in their respective countries [7-9]. While most research in Michigan has focused on white-tailed deer-cattle interactions for M. bovis transmission due to high deer densities and cattle feeding practices [10, 11], little research has been conducted on the prevalence of M. bovis in opossum $[2,12]$. In addition, no information is available on the interaction of opossum in Michigan with stored feed or hay within the confines of barns or storage facilities that opossum are known to occupy [13, 14]. Furthermore, no data are available on opossum movements and home range in the northern lower peninsula of Michigan near cattle farms.

Regardless of the efforts of management agencies in Michigan, several cattle farms test positive for M. bovis each year both inside and outside the bTB core zone as do medium-sized mammals that occupy previously depopulated farms. Previous research has documented considerable shedding of $M$. bovis by free-ranging European badgers but little similar information exists for medium-sized mammals in Michigan [15, 16]. Surveillance of medium-sized mammals in Michigan for M. bovis has found that numerous mammals may be spillover hosts but little research has been conducted to understand the amount of shedding for free-ranging mammals other than white-tailed deer (but see [17]). Studies have shown that opossum are susceptible to aerosolized inoculation [15], but lateral transmission was not documented when infected opossum were cohabited with naive opossum for 45 days [18]. Several species of mammals have been documented to use stored feed and farm structures (e.g. barns, feed silos $[12,14,19]$ ) so the potential for deposition of infective bacteria is possible. Further research on medium-sized mammals and their potential to be more than spillover hosts is warranted.

Although raccoon spatial ecology was studied in Michigan near farms that tested positive for M. bovis [14], the actual presence of other species on farms would be useful in understanding the role they play in transmission of $M$. bovis. In addition, surveillance of farms for $M$. bovis in a variety of small to medium-sized mammals would further our understanding of transmission of $M$. bovis on cattle farms in Michigan. Our first objective was to conduct surveillance in medium-sized mammals on previously depopulated cattle farms for the presence of M. bovis. Our second objective was to capture and equip opossum with Global Positioning System (GPS) technology to assess potential differences in home range and resource selection between farms inside and outside the bTB core area that have had cattle test positive for $M$. bovis. Specific interest in opossum is a result of several being diagnosed as positive on farms that had cattle test positive for M. bovis.

\section{MATERIALS AND METHODS}

We conducted our study in the northern lower peninsula of Michigan. The $8062 \mathrm{~km}^{2}$ study area included portions of Alcona, Alpena, Montmorency, Oscoda, and Presque Isle counties (Fig. 1). The area encompassed the majority of the cattle farms where $M$. bovis has been found in Michigan. We defined Deer Management Unit 452 as the bTB core area due to the high prevalence of $M$. bovis in free-ranging deer and the presence of $M$. bovis-positive cattle on farms $[4,20]$. We also selected cattle farms outside the 


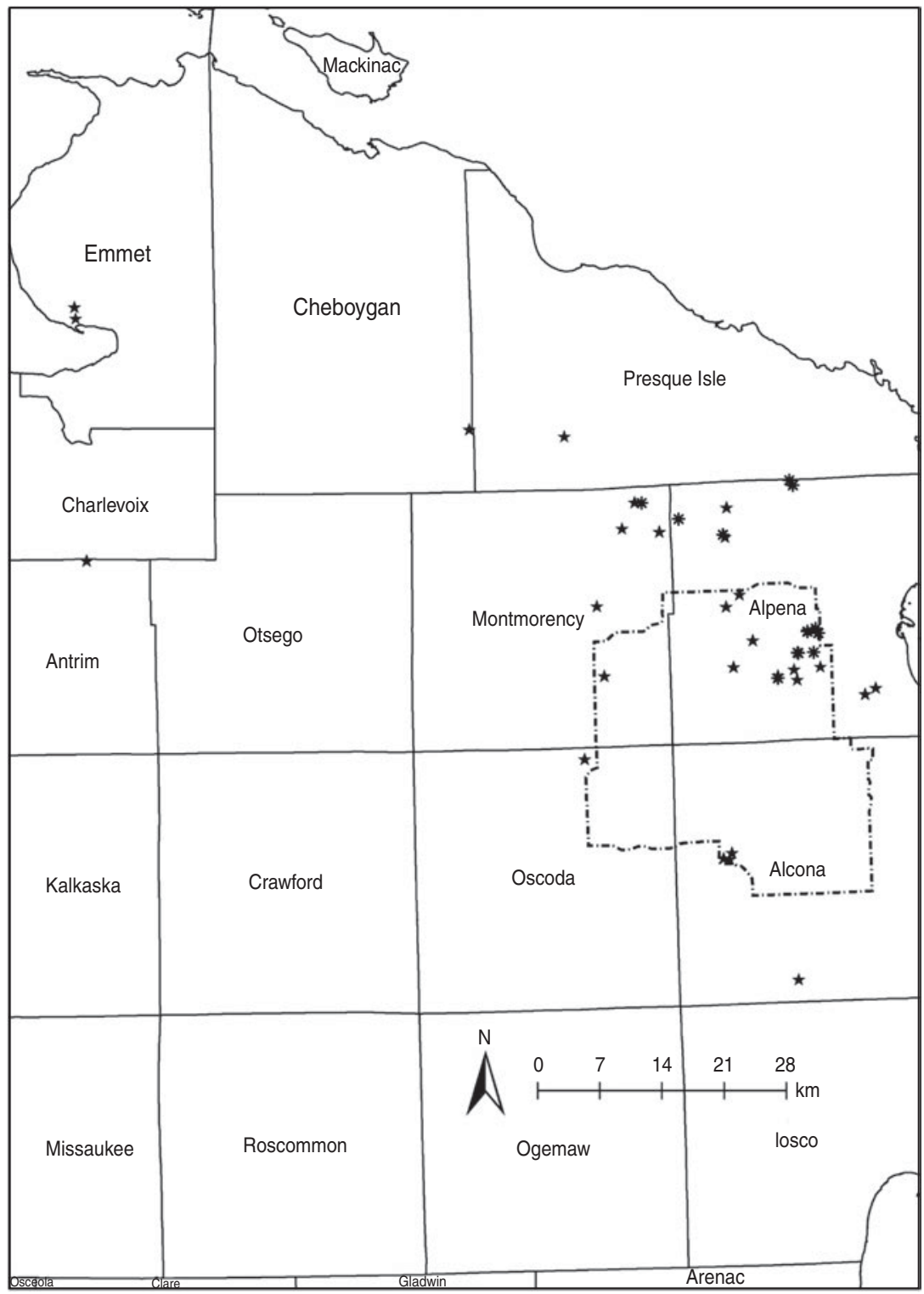

Fig. 1. Cattle farms (stars) and capture locations (asterisks) of Virginia opossum (Didelphis virginiana) inside and outside the bovine tuberculosis core area delineated by Deer Management Unit 452 (dashed polygon) used in surveillance of mammals in the northern lower peninsula of Michigan, 2006-2010.

bTB core area that have had cattle test positive for $M$. bovis for comparison. Vegetation categories that were in our study areas were combined into six classes: (1) developed, including roads, development, and barren land; (2) grass, including pasture/hay fields and native grasses; (3) agriculture, including crops; (4) forest, including upland hardwood stands (Quercus alba, Acer rubrum, A. saccharum), aspen stands (Populus tremuloides, $P$. grandidentata), hardwood/aspen mixed stands, upland conifer stands (Pinus glauca, $P$. banksiana, $P$. resinosa), and hardwood/conifer mixed stands; (5) swamp, including lowland conifer forests/swamps (P. glauca, P. mariana, Thuja occidentalis, Abies balsamea, Latrix laricinea); and (6) farms, including structures such as animal pens, silos, barns, and residential homes. Elevations in the area ranged from $150-390 \mathrm{~m}$ above sea level and the mean annual temperature was $6.6^{\circ} \mathrm{C}$, the mean rainfall was $72.5 \mathrm{~cm}$, and there was a mean snowfall of $175 \mathrm{~cm}[21]$.

From April 2006 to October 2011 raccoon and opossum were targeted for surveillance sampling on farms where cattle were depopulated after a positive test for $M$. bovis and on arbitrarily selected farms 
Table 1. Surveillance of mammals collected on farms inside the bovine tuberculosis core area (bTB) and outside the core area (non-bTB) in the northern lower peninsula of Michigan, USA, 2006-2010. Numbers within parentheses after proportions are percent prevalence where positive samples were detected

\begin{tabular}{lll}
\hline \hline Common name (scientific name) & $\begin{array}{l}\text { bTB number } \\
\text { positive/number } \\
\text { tested (\%) }\end{array}$ & $\begin{array}{l}\text { Non-bTB number } \\
\text { positive/number } \\
\text { tested (\%) }\end{array}$ \\
\hline Domestic cat (Felis catus) & $0 / 1$ & $0 / 6$ \\
Eastern cottontail (Sylvilagus floridanus) & $0 / 1$ & $0 / 7$ \\
Raccoon (Procyon lotor) & $5 / 125(4 \cdot 0)$ & $0 / 150$ \\
Striped skunk (Mephitis mephitis) & $0 / 1$ & - \\
Virginia opossum (Didelphis virginianus) & $8 / 142(5 \cdot 6)$ & $1 / 94(1 \cdot 1)$ \\
Woodchuck (Marmota monax) & $0 / 7$ & $0 / 1$ \\
Coyote (Canis latrans) & $0 / 1$ & $0 / 7$ \\
Red fox (Vulpes vulpes) & $0 / 2$ & - \\
\hline \hline
\end{tabular}

with no documented M. bovis in cattle. All surveillance on farms that were depopulated after cattle tested positive for $M$. bovis occurred within 2 years post-depopulation. Other species were periodically trapped and tested due to their close proximity to barns or at the request of the farmer. Species trapped included: opossum, raccoon, red fox, coyote, woodchuck (Marmota monax), feral cat, Eastern cottontail (Sylvilagus floridanus), and striped skunk (Mephitis mephitis). A complete list of the number of each species collected can be found in Table 1. We collected all animals using cage traps, with the exception of coyotes, which were shot with a rifle. All collections were conducted under a scientific collecting permit issued by the Wildlife Division of the Michigan Department of Natural Resources (MDNR). Animals captured alive were euthanized with a $\mathrm{CO}_{2}$ chamber or by a single gunshot to the head with a .22 calibre firearm [22] and subsequently necropsied in an aseptic mobile laboratory or at the MDNR Wildlife Disease Laboratory. Due to the manifestation of M. bovis in various tissues and organs, we collected lymph node tissues (tonsillar, retropharyngeal, tracheobronchial, mediastinal, mesenteric), a small (generally at least $5 \times 5 \mathrm{~mm}$ ) section of lung tissue, and any lesions observed [23, 24]. To increase detection, two non-lesioned pools were cultured for each animal, head and thorax tissues in one pool and abdominal tissues in a second pool [25]. Gross lesions identified on necropsy were cultured separately. All samples were kept refrigerated until they were shipped on ice to the National
Veterinary Services Laboratories at Ames, Iowa, USA (NVSL) for mycobacterial isolation and identification.

Wildlife tissue samples received at the laboratory were stored at $-20{ }^{\circ} \mathrm{C}$ (or at $-70{ }^{\circ} \mathrm{C}$ for extended periods) until processing. Individual samples were thawed, processed and decontaminated following standard protocols $[25,26]$. Briefly, samples were trimmed, soaked in a $0.065 \%$ solution of sodium hypochlorite for $15 \mathrm{~min}$, placed in individual sterilized pint jars, covered with Phenol Red broth and then mixed by securing a blade unit and gasket on the jars, inverting and blending for $30 \mathrm{~s}$ or until liquefied. Samples were then transferred to $50 \mathrm{ml}$ centrifuge tubes and decontaminated with a $1.6 \%$ final concentration of sodium hydroxide for 7-10 min and neutralized to effect with hydrochloric acid. Samples were then spun in a refrigerated centrifuge at $4800 \mathrm{~g}$ for 20 min. Both BACTEC 12B (Becton Dickinson, USA) and MGIT 9360 media (Becton Dickinson) were inoculated with $500 \mu \mathrm{l}$ of sample suspension. Media signalling positive were examined with a Ziehl-Neelsen acid-fast staining technique. Acid-fast positive bacteria were screened using AccuProbe M. tuberculosis complex nucleic acid probes (GenProbe, USA) to determine if the acid-fast bacteria were of the M. tuberculosis complex. Mycobacterium bovis was distinguished from $M$. tuberculosis isolates by spoligotyping [27]. Information collected on each animal sampled for $M$. bovis included date of death, date of sample collection, species, sex, and location. 
We used the epitools package in Program R (function binom.exact; $\mathrm{R}$ Foundation for Statistical Computing, Austria) to calculate the prevalence, the odds ratio (function oddsratio), and 95\% confidence interval (CI) to compare differences in prevalence across space, time, and demographic groups (i.e. area). To further describe the effects of exposure to farm environments that had cattle test positive for $M$. bovis, we also calculated the prevalence of opossum and raccoon that occupied farms that had cattle test positive for $M$. bovis to those that occupied farms that did not have cattle test positive for $M$. bovis with a one-tail probability, $Z$ test of proportions.

We live-captured 50 opossum from 1 April to 15 July 2011 , using $42 \times 15 \times 15$ inch single-door cage traps in and around farms selected for inclusion in the study (Fig. 1). We handled all opossum without chemical immobilization using commercially available 52-inch reptile tongs to grasp the opossum and remove it from the trap, and then placed it into a cat carrier bag that fully contained the body but exposed the head and neck of the opossum. For each opossum, we recorded sex, morphometric data, marked with individually numbered metal ear tags, injected passive integrated transponder tags (PIT tags) and attached a GPS collar model G2C171 with a very high frequency (VHF) mortality sensor (model G2C171, $115 \mathrm{~g}$; Sirtrack Wildlife Tracking Solutions, New Zealand). The duty cycle for GPS collars was on nocturnally for $12 \mathrm{~h}$ and a relocation was attempted every $3 \mathrm{~h}$. To account for high mortality of captured opossum, we re-used GPS collars that were not in use for $>1$ month. We attempted to locate all opossum at least once per week with the built-in VHF component to determine location and source of natural mortality. We estimated survival of collared opossum using Kaplan-Meier estimators and set our period for analysis at 2 weeks due to the low survival of opossum identified in previous research [28]; the survival period ended 30 September 2011.

Upon completion of the study, 1 October 2011, we initiated trapping in areas that GPS-collared opossum occupied. We trapped and euthanized opossum using a $\mathrm{CO}_{2}$ chamber [22]. If we were unable to trap GPS-collared opossum, they were located by radiotracking, captured by reptile tongs, and euthanized in a $\mathrm{CO}_{2}$ chamber. Euthanasia and recovery of study animals was necessary to retrieve data collected in GPS collars for detailed information on movements and home range. Euthanasia also was necessary to determine the presence/absence of M. bovis in study animals by collecting tissue samples as previously described. Upon recovery of GPS-collared opossum, biological samples were collected and kept refrigerated prior to being shipped to the NVSL for M. bovis culture.

For comparison to previous studies, we estimated home range using several fixed kernel density estimators (KDE) [29, 30]. We used KDE with the univariate reference or default bandwidth $\operatorname{KDE}\left(\mathrm{h}_{\mathrm{ref}}\right)$. Estimation with $\mathrm{h}_{\mathrm{ref}}$ typically is not reliable for use on multimodal datasets because it results in oversmoothing of home ranges [31, 32] so we also used KDE with least squares cross-validation $\left(\mathrm{h}_{\mathrm{lscv}}\right)$ that has been suggested instead of $h_{\text {ref }}$ [33]. Finally, in comparison to first-generation methods of KDE (i.e. $h_{r e f}$, $\mathrm{h}_{\text {lscv }}$ ), we present a second-generation method, the bivariate plug-in bandwidth selection $\left(\mathrm{h}_{\text {plug-in }}\right)$ that performs well even when analysing dependent data common with locations collected with GPS technology [34]. All KDE were calculated using the adehabitatHR and ks packages in Program R (R Foundation for Statistical Computing, Austria) [35]. A two-way analysis of variance was used to determine differences in size of home range between sex and bTB core area (bTB $v s$. non-bTB) with significance considered at $P<0 \cdot 05$. We did not test for difference between size of home range and estimator because contrasts among estimators were expected.

We selected farms for equipping opossum with GPS collars based on their proximity to forested habitat that provided similar landscape characteristics preferred by opossum (i.e. proximity to forest patches), to maximize species density in our study design [14], and that had active cattle operations. Because we were interested in understanding potential differences in use of farms inside and outside the bTB core area, we selected some farms based on previous detection of $M$. bovis in cattle herds and white-tailed deer; however, it was not possible to select all farms positive for $M$. bovis because some operations closed and no longer had cattle after a previous positive test for $M$. bovis. We attempted to trap two opossum near structures (i.e. barns, silos) and two opossum in the surrounding forested habitat at each farm to assess potential for use of structures by residents or visitors to these structures. Each farm served as a replicate in our study design.

We estimated a population-level resource selection function (RSF) using a mixed-effects logistic regression model. For RSF analysis, we used the 
lmer function (family=binomial) from the lme4 package in Program R (R Foundation for Statistical Computing, Austria). We compared GPS locations to the same number of random points drawn from within individual opossum KDE home range estimated with $\mathrm{h}_{\text {ref }}$ in a type III study design [36]. Using logistic regression with use-availability data presents some problems because predicted values are not scaled between 0 and 1 and generally do not reflect true probabilities of resource selection $[36,37]$, but logistic regression can provide an informative and unbiased method for ranking habitat use and for comparing relative probability of use [37, 38]. We used individual opossum as a random-intercept effect in our mixed-effects logistic regression analysis to address issues associated with autocorrelation and uneven sample sizes between individuals [39]. We created seven a priori models and an intercept model using Akaike's Information Criterion for model selection [40].

\section{RESULTS}

We sampled mammals on 14 farms inside the bTB core area and 16 farms outside the bTB core area (Fig. 1). M. bovis was not isolated from mammals surveyed other than raccoon and opossum (Table 1). Overall, 13 medium-sized mammals (eight opossum, five raccoon) tested positive for $M$. bovis inside the bTB core area and only one outside the bTB core area. Due to the low overall number of opossum and raccoon positive for $M$. bovis, odds ratios could not be estimated. Prevalence in opossum on farms inside the bTB core area was comparable $(5.6 \%$, $95 \%$ CI $2 \cdot 0-11 \cdot 0)$ to prevalence in raccoon $(4.0 \%$, $95 \%$ CI $1 \cdot 0-9 \cdot 0, P<0 \cdot 001)$. Only one opossum tested positive for $M$. bovis $(1 \%, 95 \%$ CI $0 \cdot 03-5 \cdot 8)$ but no raccoon tested positive on farms outside the bTB core area (Table 1). Prevalence in opossum occupying farms that had cattle test positive for $M$. bovis was higher $(6 \cdot 4 \%)$ than opossum occupying farms that never had cattle test positive for M. bovis $(0.9 \%$, $P=0 \cdot 01$ ). Prevalence in raccoon occupying farms that had cattle test positive for $M$. bovis was similar $(1.9 \%)$ to raccoon occupying farms that never had cattle test positive for $M$. bovis $(1.7 \%, P=0.45)$. None of the eight opossum equipped with a GPS collar and euthanized at the completion of the study were positive for M. bovis.

We captured and equipped 48 individual opossum with GPS collars and PIT tags from April to
mid-July 2011. Due to slipped collars, lost signals, and unrecoverable carcasses, we were not able to document sources of mortality for all opossum and estimates of survival were conducted with censored data. The Kaplan-Meier estimate of survival was $35 \%$ for opossum with known fates for the duration of the study period. Mortality sources included drowning in a farm catchment pond, roadkill, harvest by human, and one possibly predation by a black bear. Two opossum appeared to have died for unknown reasons in a subterranean den because a collar signal was detected, but the collar was not recovered despite hours of effort.

Five female and five male opossum met our minimum sample size requirement of $\geqslant 25$ locations and being monitored for $\geqslant 30$ days for estimates of home range inside and outside the bTB core area (Table 2, Fig. 2). Mean ( \pm s.D.) size of home range for $50 \%$ estimates with $h_{\text {ref }}, h_{\text {lscv }}$, and $h_{\text {plug-in }}$ were $39 \cdot 6 \pm 28.5$ ha, $10 \cdot 9 \pm 11 \cdot 2$ ha, and $14 \cdot 7 \pm 12 \cdot 5$ ha, respectively. Mean ( \pm s.D.) size of home range for $95 \%$ estimates with $h_{\text {ref }}$,

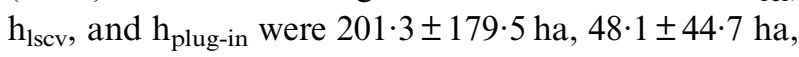
and $65 \cdot 4 \pm 49 \cdot 1$ ha, respectively. Mean ( \pm s.D.) size of home range for $50 \%$ and $95 \%$ estimates was similar by sex $(P=0.791)$ and bTB zone (inside or outside the bTB core area, $P=0 \cdot 218)$, with no interaction of sex and bTB zone $(P=0.365)$ regardless of the estimator used (Fig. 2). Results of resource selection analysis identified farms and bTB zone as having the most support of all models evaluated. Vegetation and zone provided $56 \%$ of model weights and the addition of sex provided an additional 22\% (Table 3). Parameter estimates indicated that opossum selected farms over any other habitat and selection of habitat by opossum differed between farms inside and outside the bTB core area (Table 4).

\section{DISCUSSION}

We identified two species of medium-sized mammals that were positive for $M$. bovis on farms after the cattle tested positive for $M$. bovis. Although overall sample size limited statistical significance, 13 positive medium-sized mammals were from within the bTB core area while only one was from outside the bTB core area. While numerous studies on captive inoculated medium-sized mammals have stated that smalland medium-sized mammals likely do not shed enough $M$. bovis to be considered as reservoirs for $M$. bovis [15, 18], medium-sized mammals such as brushtail possum in New Zealand and badgers in 
Table 2. Size of home range (hectares), days on air, and number of locations used to estimate size of home range of GPS-collared Virginia opossum (Didelphis virginiana) around farms in Michigan, USA, April-September 2011. Home range was reported for 50\% and 95\% fixed kernel density estimation using the reference bandwidth ( $h_{\text {ref }}$ ), least-square cross validation $\left(h_{l s c v}\right)$, plug-in $\left(h_{\text {plug-in }}\right)$ bandwidth selection

\begin{tabular}{|c|c|c|c|c|c|c|c|c|c|}
\hline \multirow[b]{2}{*}{ ID } & \multirow[b]{2}{*}{ Sex } & \multirow{2}{*}{$\begin{array}{l}\text { Days } \\
\text { on air }\end{array}$} & \multirow[b]{2}{*}{ Locations } & \multicolumn{2}{|l|}{$\mathrm{h}_{\mathrm{ref}}$} & \multicolumn{2}{|l|}{$\mathrm{h}_{\mathrm{lscv}}$} & \multicolumn{2}{|l|}{$\mathrm{h}_{\text {plug-in }}$} \\
\hline & & & & $50 \%$ & $95 \%$ & $50 \%$ & $95 \%$ & $50 \%$ & $95 \%$ \\
\hline 69 & $\mathrm{~F}$ & 77 & 26 & 47 & 181 & 36 & 144 & 19 & 79 \\
\hline 109 & M & 85 & 71 & 35 & 155 & 9 & 46 & 18 & 79 \\
\hline 191 & $\mathrm{~F}$ & 124 & 33 & 22 & 104 & 10 & 52 & 14 & 45 \\
\hline 380 & $\mathrm{~F}$ & 85 & 64 & 69 & 292 & 10 & 48 & 30 & 127 \\
\hline 581 & $\mathrm{~F}$ & 55 & 25 & 11 & 79 & 0 & 1 & 0 & 9 \\
\hline 620 & M & 35 & 25 & $0 \cdot 26$ & $1 \cdot 3$ & $0 \cdot 13$ & 0.58 & 0.08 & $0 \cdot 33$ \\
\hline 681 & M & 93 & 69 & 85 & 312 & 21 & 91 & 38 & 147 \\
\hline 761 & $\mathrm{~F}$ & 63 & 44 & 74 & 635 & 4 & 25 & 11 & 96 \\
\hline 840 & M & 90 & 29 & 36 & 164 & 16 & 66 & 11 & 50 \\
\hline \multirow[t]{2}{*}{931} & M & 74 & 33 & 17 & 89 & 2 & 7 & 4 & 22 \\
\hline & & & Mean ( \pm s.D.) & $39 \cdot 6(28 \cdot 5)$ & $201 \cdot 3(179 \cdot 5)$ & $10 \cdot 9(11 \cdot 2)$ & $48 \cdot 1(44 \cdot 7)$ & $14 \cdot 7(12 \cdot 5)$ & $65 \cdot 4(49 \cdot 1)$ \\
\hline
\end{tabular}

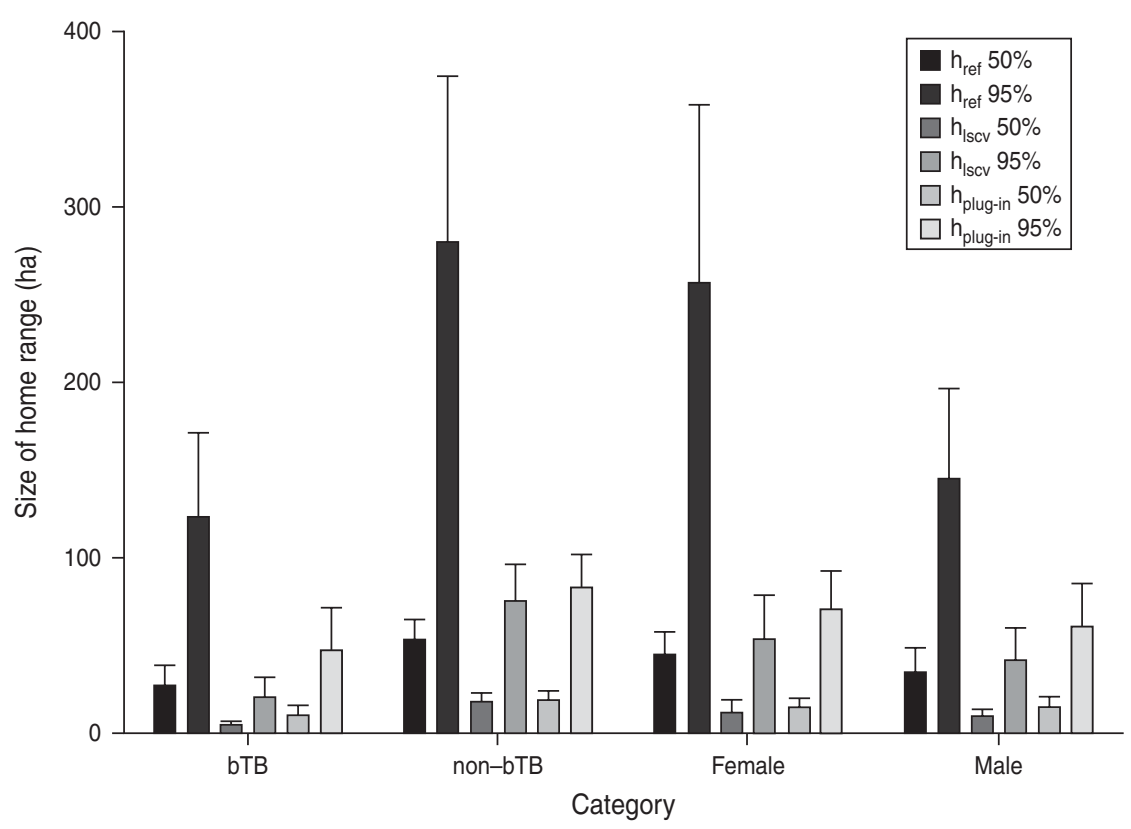

Fig. 2. Size of home range for GPS-collared Virginia opossum (Didelphis virginiana) in the northern lower peninsula of Michigan inside and outside the bovine tuberculosis (bTB) core area, April-September 2011. Home range was reported for $50 \%$ and $95 \%$ fixed kernel density estimation using the reference bandwidth $\left(\mathrm{h}_{\text {ref }}\right)$, least-square cross validation $\left(\mathrm{h}_{\mathrm{lscv}}\right)$, plug-in $\left(\mathrm{h}_{\text {plug-in }}\right)$ bandwidth selection.

the UK and Ireland are considered primary reservoirs of $M$. bovis [41, 42]. Furthermore, prevalence of $M$. bovis in free-ranging white-tailed deer has held steady for the past 4 years at just below 2\% [43] which is lower than prevalence for opossum and raccoon in our study. Changing management strategies resulting in less dense populations of white-tailed deer, minimizing deer use of farm environments in Michigan [5, 44], and results from our surveillance efforts suggest that the role of medium-sized mammals as spillover hosts or potential routes of transmission to cattle deserves considerable attention.

Survival of opossum in northern latitudes long enough to ingest and shed enough $M$. bovis to be 
Table 3. Models, along with the intercept-only model, identified by Akaike's Information Criterion (AIC), $\triangle A I C$, and AIC weights $\left(w_{i}\right)$ from the mixed-effects logistic regression analysis of Virginia opossum (Didelphis virginiana) resource selection in the northern lower peninsula Michigan, USA, April-September 2011

\begin{tabular}{lllrl}
\hline \hline Model parameters & D.F. & AIC & $\Delta$ AIC & $w_{i}$ \\
\hline Vegetation + zone+(1|ID) & 7 & $1066 \cdot 5$ & $0 \cdot 00$ & $0 \cdot 5622$ \\
Vegetation + sex + zone + & 8 & $1068 \cdot 4$ & $1 \cdot 90$ & $0 \cdot 2174$ \\
$\quad(1 \mid$ ID) & & & & \\
Vegetation + (1|ID) & 6 & $1069 \cdot 0$ & $2 \cdot 50$ & $0 \cdot 1611$ \\
Vegetation + sex + (1|ID) & 7 & $1071 \cdot 0$ & $4 \cdot 50$ & $0 \cdot 0593$ \\
$(1 \mid$ ID $)$ & 2 & $1165 \cdot 7$ & $99 \cdot 20$ & $0 \cdot 0000$ \\
Sex $+(1 \mid$ ID) & 3 & $1167 \cdot 7$ & $101 \cdot 20$ & $0 \cdot 0000$ \\
Zone+(1|ID) & 3 & $1167 \cdot 7$ & $101 \cdot 20$ & $0 \cdot 0000$ \\
Sex + zone + (1|ID) & 4 & $1169 \cdot 7$ & $103 \cdot 20$ & $0 \cdot 0000$ \\
\hline \hline
\end{tabular}

considered a reservoir for M. bovis is not known. Survival of opossum has been documented to range from $17 \%$ to $63 \%$ in various regions of the USA $[28,29]$ and has been difficult to study. Low survival rates in our study (i.e. 35\%) appear to be comparable to others with mortality sources ranging from drowning to predation by a black bear. Considerable movements by males has also been documented to contribute to mortality and difficulty in tracking opossum with radio-collars due to dispersal and movements over large distances in a short period of time [30, 45]. Opossum survival rarely exceeds 2 years and few survive more than a single summer, further complicating research on exposure to and transmission of $M$. bovis [29, 45]. Although our study was not designed to monitor annual survival, opossum and raccoon that were culture-positive for $M$. bovis on farms previously depopulated of $M$. bovispositive cattle suggests direct contact with cattle or an indirect means of transmission of M. bovis.

Although our study did not set out to document direct observations of cattle and opossum, only one direct contact of cattle with a raccoon but none with opossum was found in a separate study in Michigan [19]. A raccoon was identified with infrared cameras coming face-to-face at about $3 \mathrm{~m}$ with cattle on one occasion in another study on farms in Michigan [12]. Although direct transmission of M. bovis from cattle to opossum seems unlikely, our study shows that opossum are more likely to be infected with $M$. bovis if they are potentially exposed to infected cattle. Opossum being infected with $M$. bovis could
Table 4. Parameter estimates, standard error, and $P$ values for the model with the most support for Virginia opossum (Didelphis virginiana) resource selection in the bovine tuberculosis (bTB) and non-TB core areas of the northern lower peninsula Michigan, USA, April-September 2011

\begin{tabular}{|c|c|c|c|c|}
\hline Covariate & Estimate & S.E. & $z$ value & $P$ \\
\hline Intercept & $-0 \cdot 3739$ & 0.0932 & $-4 \cdot 010$ & $<0 \cdot 001$ \\
\hline Agriculture & $0 \cdot 0572$ & $0 \cdot 1547$ & $0 \cdot 370$ & 0.7114 \\
\hline Forest & $0 \cdot 2118$ & $0 \cdot 1514$ & $1 \cdot 399$ & $0 \cdot 1618$ \\
\hline Wetland & 0.0956 & $0 \cdot 1165$ & $0 \cdot 821$ & $0 \cdot 4118$ \\
\hline Farms & $1 \cdot 4445$ & $0 \cdot 1584$ & $9 \cdot 120$ & $<0 \cdot 001$ \\
\hline Non-TB core area & $0 \cdot 2010$ & $0 \cdot 0947$ & $2 \cdot 123$ & 0.0337 \\
\hline
\end{tabular}

be from an indirect source, but we cannot eliminate the possibility that opossum were infected through direct contact with live or dead white-tailed deer or cattle. Although most farms are depopulated when cattle test positive for $M$. bovis, complete removal of stored feed and sanitization of feed storage facilities are not required. Opossum were observed and captured in barns, silos, and under storage facilities that contained stored feed.

Estimates of home range of opossum in our study identified sizes comparable to studies in other regions with opossum potentially using more than a single farm (Fig. 3). Several opossum appeared to use more wooded areas in their home range while others concentrated their home range on farms or farm structures. Upon study completion, we captured one opossum inside a barn used to store old household and farm equipment where the owner fed open bags of dry food to feral cats. Other daytime relocations of radio-collared opossum included inside tree root cavities, an underground cavern in forested habitat, a slash pile of wood and debris, and under the floor of an abandoned shed; the latter two locations were within $50 \mathrm{~m}$ of farm structures. Although all opossum were not documented to use farms and farm structures exclusively, use of farms was documented on a regular basis for several of our GPS-collared opossum (Fig. 3).

Third-order resource selection confirmed that opossum used farms and farm structures on a regular basis identifying the potential for exposure to M. bovis through contaminated sources. Although farms were not sampled for contaminated sources in this study, three farms that had cattle test positive for M. bovis in Michigan had 455 samples of soil, water, feed, 


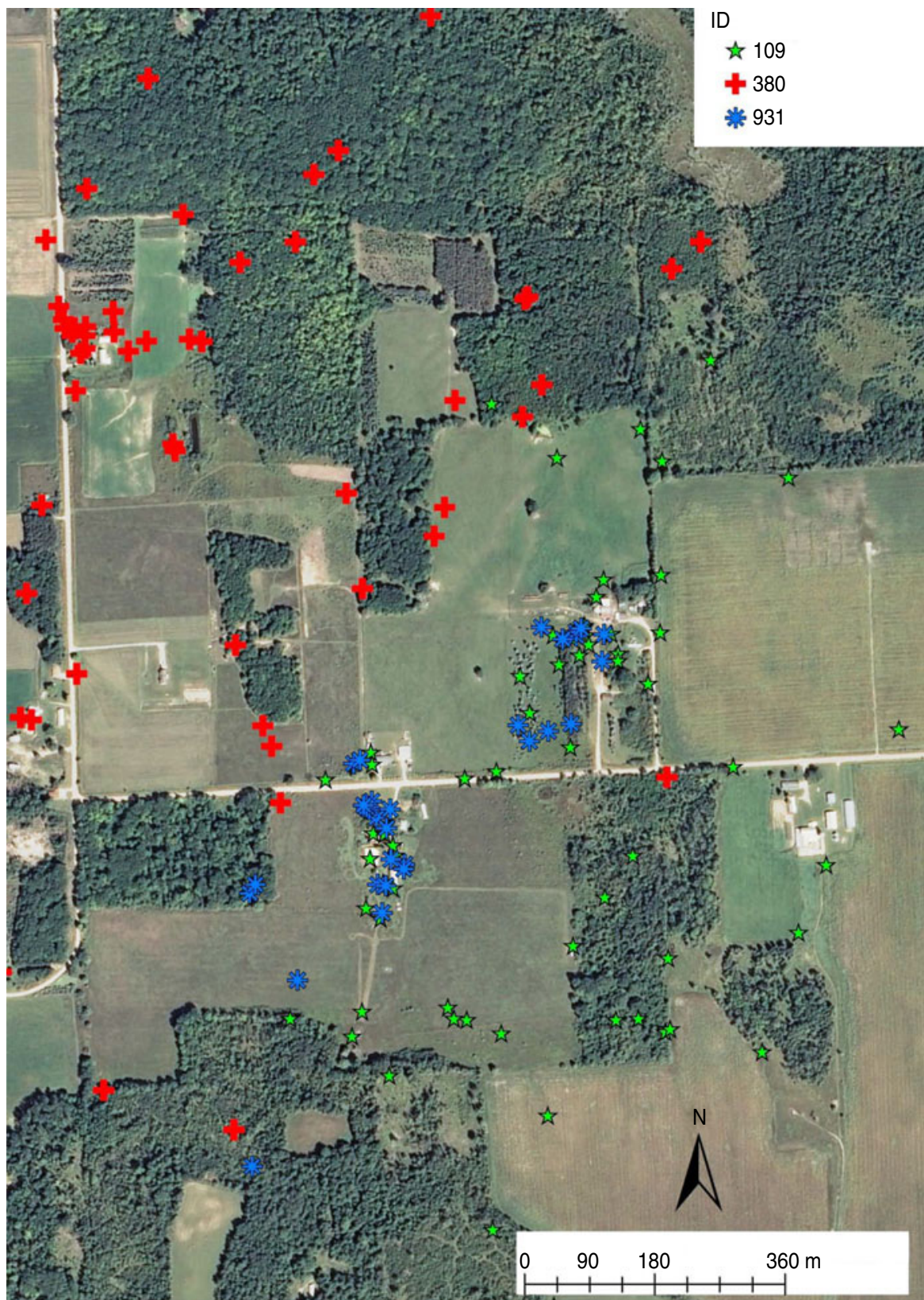

Fig. 3. Locations of GPS-collared Virginia opossum (Didelphis virginiana) that occupied forests and farms on a regular basis in the northern lower peninsula of Michigan inside the bovine tuberculosis core area, April-September 2011.

hay, pasture grass, livestock faeces, deer faeces, and carnivore faeces tested with none positive for $M$. bovis [12]. Using infrared cameras in barns, $17.4 \%$ of observations were in barns that cattle occupied; however, raccoons were the most common species observed in barns [12]. Although we did not specifically monitor barn use by our GPS-collared opossum, it is reasonable to infer that resource selection near farms could lead to a greater potential for ingestion of $M$. bovis on a regular basis for both sexes of opossum. Until opossum are trapped on farms or in natural settings and tested for M. bovis and subsequently tested for shedding of $M$. bovis in saliva, urine, or faeces, assertions that opossum are not able to shed enough bacteria to act as vectors for $M$. bovis cannot be conclusively established. Furthermore, until Michigan becomes a bTB-free state and no farms have cattle that test positive for $M$. bovis, all possible avenues of transmission and survival of $M$. bovis should be explored. 
In conclusion, surveillance identified two wildlife species that tested positive for M. bovis on farms in the northern lower peninsula of Michigan. Although surveillance of mammals and monitoring of GPS-collared opossum were not done on the same farms during the same period, valuable insight was gained from both portions of the study. Opossum infected with $M$. bovis were more likely to be found in the bTB core area and on contaminated farms (i.e. with cattle positive for $M$. bovis) suggesting that opossum acquire $M$. bovis by direct or indirect means when they occupy such environments. Although detection of $M$. bovis in environmental samples is difficult [12], use of farms by GPS-collared opossum and recovery of live opossum on farms suggests that indirect transmission of M. bovis to opossum is possible. Further sampling designs to test environmental samples on farms for $M$. bovis from areas known to attract opossum on a regular basis would further our understanding on the potential for indirect transmission to medium-sized mammals in Michigan. Given the ongoing infections of cattle with M. bovis in Michigan, research should be continued to further our understanding of opossum, raccoon, and white-tailed deer resource selection and infection patterns on and around farms to provide further elucidation of the ecology of M. bovis in the region.

\section{ACKNOWLEDGEMENTS}

Funding was provided by the United States Department of Agriculture, Animal Plant and Health Inspection Service, Wildlife Services and Veterinary Services, National Wildlife Research Center. We thank Tony Aderman, Dane Williams and Rex Schenk for planning and assistance in surveillance and trapping efforts. We also thank the Michigan Department of Natural Resources for use of their Wildlife Disease Laboratory for conducting necropsies.

\section{DECLARATION OF INTEREST}

None.

\section{REFERENCES}

1. Schmitt SM, et al. Bovine tuberculosis in free-ranging white-tailed deer from Michigan. Journal of Wildlife Diseases 1997; 33: 749-758.
2. Bruning-Fann CS, et al. Bovine tuberculosis in freeranging carnivores from Michigan. Journal of Wildlife Diseases 2001; 37: 58-64.

3. O'Brien DJ, et al. Estimating the true prevalence of Mycobacterium bovis in free-ranging elk in Michigan. Journal of Wildlife Diseases 2008; 44: 802-810.

4. Okafor CC, et al. Descriptive epidemiology of bovine tuberculosis in Michigan (1975-2010): lessons learned. Veterinary Medicine International 2011; 2011: 874924.

5. Walter WD, et al. On-farm mitigation of transmission of tuberculosis from white-tailed deer to cattle: literature review and recommendations. Veterinary Medicine International 2012; 2012.

6. Hutchings MR, et al. Effects of farm management practices on cattle grazing behaviour and the potential for transmission of bovine tuberculosis from badgers to cattle. The Veterinary Journal 1997; 153: 149-162.

7. Ramsey D, et al. The effects of reducing population density on contact rates between brushtail possums: implications for transmission of bovine tuberculosis. Journal of Applied Ecology 2002; 39: 806-818.

8. Caley $\mathbf{P}$, et al. The effect of manipulating population density on the probability of den-sharing among common brushtail possums, and the implications for transmission of bovine tuberculosis. Wildlife Research 1998; 25: 383-392.

9. Bohm M, et al. The spatial distribution of badgers, setts and latrines: the risk for intra-specific and badgerlivestock disease transmission. Ecography 2008; 31: 525-537.

10. Garner MS. Movement patterns and behavior at winter feeding and fall baiting stations in a population of white-tailed deer infected with bovine tuberculosis in the northeastern lower peninsula of Michigan. East Lansing: Michigan State University, 2001, pp. 1-293.

11. Miller R, et al. Evaluation of the influence of supplemental feeding of white-tailed deer (Odocoileus virginianus) on the prevalence of bovine tuberculosis in the Michigan wild deer population. Journal of Wildlife Diseases 2003; 39: 84-95.

12. Witmer G, et al. Epizootiological survey of bovine tuberculosis in northern Michigan. Journal of Wildlife Diseases 2010; 46: 368-378.

13. Garnett BT, et al. Use of cattle farm resources by badgers (Meles meles) and risk of bovine tuberculosis (Mycobacterium bovis) transmission to cattle. Proceedings of the Royal Society of London, Series $B$ 2002; 269: 1487-1491.

14. Atwood TC, et al. Spatial ecology of raccoons related to cattle and bovine tuberculosis in northeastern Michigan. Journal of Wildlife Management 2009; 73: 647-654.

15. Fitzgerald SD, et al. Experimental aerosol inoculation of Mycobacterium bovis in North American opossums (Didelphis virginiana). Journal of Wildlife Diseases 2003; 39: 418-423.

16. Clifton-Hadley RS, et al. Mycobacterium bovis in the European badger (Meles meles): epidemiological findings in tuberculosis badgers from a naturally infected population. Epidemiology and Infection 1993; 111: 9-19. 
17. State of Michigan. Proceedings of the Michigan Bovine Tuberculosis Eradication Project Activities Report. Lansing: Michigan Department of Community Health, 2008, pp. 1-36.

18. Fenton KA, et al. Experimental aerosol inoculation and investigation of potential lateral transmission of Mycobacterium bovis in Virginia opossum (Didelphis virginiana). Veterinary Medicine International 2012; 2012.

19. Hill JA, Wildlife-cattle interactions in northern Michigan: implications for the transmission of bovine tuberculosis (thesis). Logan: Utah State University, 2005, pp. 1-58.

20. O'Brien DJ, et al. Estimating the true prevalence of Mycobacterium bovis in hunter-harvested white-tailed deer in Michigan. Journal of Wildlife Diseases 2004; 40: $42-52$.

21. Hughey BD, Are there 'hot spots' of bovine tuberculosis in the free-ranging white-tailed deer (Odocoileus virginianus) herd of northeastern Michigan? East Lansing: Michigan State University, 2003, pp. 1-86.

22. American Veterinary Medicine Association (AVMA). AVMA guidelines for the euthanasia of animals. 2007 (http://www.avma.org/issues/animal_welfare/euthanasia. pdf). Accessed 7 August 2012.

23. Palmer MV, et al. Aerosol exposure of white-tailed deer (Odocoileus virginianus) to Mycobacterium bovis. Journal of Wildlife Diseases 2003; 39: 817-823.

24. Clarke KR, et al. Experimental inoculation of meadow voles (Microtus pennsylvanicus), house mice (Mus musculus), and Norway rats (Rattus norvegicus) with Mycobacterium bovis. Journal of Wildlife Diseases 2007; 43: 353-365.

25. de Lisle GW, et al. Tuberculosis in free-ranging wildlife: detection, diagnosis and management. Revue Scientifique et Technique de l'Office International des Épizooties 2002; 21: 317-334.

26. Hines $\mathbf{N}$, et al. Comparison of the recovery of Mycobacterium bovis isolates using the BACTEC MGIT 960 system, BACTEC 460 system, and Middlebrook 7H10 and 7H11 solid media. Journal of Veterinary Diagnostic Investigation 2006; 18: 243-250.

27. Roring S, et al. Rapid diagnosis and strain differentiation of Mycobacterium bovis in radiometric culture by spoligotyping. Veterinary Microbiology 1998; 61: 71-80.

28. Gipson PS, et al. Survival and home ranges of opossums in northeastern Kansas. The Southwestern Naturalist 2001; 46: 178-182.

29. Sunquist ME, et al. Movement patterns and home range in the common opossum (Didelphis virginiana). Journal of Mammalogy 1987; 68: 173-176.
30. Gillette LN. Movement patterns of radio-tagged opossums in Wisconsin. American Midland Naturalist 1980; 104: $1-12$.

31. Worton BJ. Using Monte Carlo simulation to evaluate kernel-based home range estimators. Journal of Wildlife Management 1995; 59 794-800.

32. Seaman DE, et al. Effects of sample size on kernel home range estimates. Journal of Wildlife Management 1999; $63739-747$.

33. Rodgers AR, et al. HRT: home range tools for ArcGIS 2010. Ontario Ministry of Natural Resources, Centre for Northern Forest Ecosystem Research (http://flash. lakeheadu.ca/ arodgers/hre/). Accessed 11 March 2013.

34. Hall P, et al. On bandwidth choice for density estimation with dependent data. Annals of Statistics 1995; 23: 2241-2263.

35. Calenge C. The package 'adehabitat' for the R software: a tool for the analysis of space and habitat use by animals. Ecological Modelling 2006; 197: 516-519.

36. Manly BFJ, et al. Resource Selection by Animals: Statistical Design and Analysis for Field Studies. Dordrecht: Kluwer Academic Publishers, 2002.

37. Keating KA, et al. Use and interpretation of logistic regression in habitat-selection studies. Journal of Wildlife Management 2004; 68: 774-789.

38. Johnson CJ, et al. Resource selection functions based on use-availability data: theoretical motivation and evaluation methods. Journal of Wildlife Management 2006; 70: $347-357$.

39. Gillies CS, et al. Application of random effects to the study of resource selection by animals. Journal of Animal Ecology 2006; 75: 887-898.

40. Burnham KP, et al. Model Selection and Multimodel Inference: a Practical Information-Theoretic Approach. New York: Springer-Verlag, 2002, pp. 1-488.

41. Corner LAL, et al. Mycobacterium bovis infection in the Eurasian badger (Meles meles): the disease, pathogenesis, epidemiology, and control. Journal of Comparative Pathology 2011; 144: 1-24.

42. Jackson R, et al. Naturally occurring tuberculosis caused by Mycobacterium bovis in brushtail possums (Trichosurus vulpecula). III. Routes of infection and excretion. New Zealand Veterinary Journal 1995; 43: 322-327.

43. O'Brien DJ, et al. Management of bovine tuberculosis in Michigan wildlife: current status and near term prospects. Veterinary Microbiology 2011; 151: 179-187.

44. O'Brien DJ, et al. Managing the wildlife reservoir of Mycobacterium bovis: the Michigan, USA, experience. Veterinary Microbiology 2006; 112: 313-323.

45. Fitch HS, et al. A radiotelemetric study of a spatial relationships in the opossum. American Midland Naturalist 1970; 84: 170-186. 